\title{
IDENTIFICAÇÃO TAXONÔMICA DE PLANTAS MEDICINAIS USADAS NO MACIÇO DE BATURITÉ, NO CEARÁ
}

\author{
Carlos Henrique Silva Pinheiro ${ }^{1}$ \\ Ana Karolyne Ancelmo Freire ${ }^{2}$
}

\begin{abstract}
RESUMO
A utilização de plantas medicinais está marcada na história do desenvolvimento da humanidade e, ainda hoje, é comum ver alguma espécie cultivada em residências brasileiras, tanto em jarros, como em jardins e canteiros que consorciam várias plantas medicinais. Nesse contexto, o trabalho pretende identificar, discutir e classificar três das espécies encontradas, através de uma pesquisa exploratória de campo, em residências visitadas em cidades do Maciço de Baturité, zona serrana do estado do Ceará. Somando-se a essa pesquisa exploratória, realizou-se uma pesquisa bibliográfica a respeito das classificações e usos das plantas coletadas. Constatou-se que são três as espécies mais encontradas nos estabelecimentos, sendo estas a Alfavaca (Ocimum basilicum L.), o Boldo-da-terra (Plectranthus barbatus A.) e o Coirama-Branco (Bryophyllum pinnatum (Lam.).
\end{abstract}

Palavras-chave: Fitoterápicos. Saúde urbana. Etnobotânica.

\section{TAXONOMIC IDENTIFICATION OF MEDICINAL PLANTS USED IN THE BATURITÉ MOUNTAIN RANGE, IN CEARÁ}

\section{ABSTRACT}

The use of medicinal plants is marked in the history of human development and, even today, it is common to see some species cultivated in Brazilian homes, both in jars, as well as in gardens and flower beds that combine various medicinal plants. In this context, the work intends to identify, discuss and classify three of the species found, through an exploratory field research, in homes visited in the cities of Maciço de Baturite, mountainous zone of the state of Ceará. In addition to this exploratory research, a bibliographical research was carried out regarding the classifications and uses of the collected plants. Three species were found to be most commonly found in establishments, namely the Alfavaca (Ocimum basilicum L.), the Boldo-da-terra (Plectranthus barbatus A.) and the Coirama-Branco(Bryophyllum pinnatum (Lam.).

Keywords: Herbal Medicines. Urban health. Ethnobotany.

\section{IDENTIFICACIÓN TAXONÓMICA DE PLANTAS MEDICINALES UTILIZADAS EN EL MACIZO DE BATURITÉ, EN CEARÁ}

\section{RESUMEN}

El uso de plantas medicinales está marcado en la historia del desarrollo humano y, aún hoy, es común ver algunas especies cultivadas en hogares brasileños, tanto en tinajas como en jardines y parterres que combinan diversas plantas medicinales. En este contexto, el trabajo pretende identificar, discutir y clasificar tres de las especies encontradas, a través de una investigación exploratoria de campo, en hogares visitados en las ciudades de Maciço de Baturité, zona montañosa del estado de Ceará. Además de esta investigación exploratoria, se realizó una investigación bibliográfica sobre las clasificaciones y usos de las plantas recolectadas. Se encontró que tres especies se encuentran más comúnmente en los establecimientos, a saber, Alfavaca (Ocimum basilicum L.), Boldo-da-terra (Plectranthus barbatus A.) y Coirama-Branco (Bryophyllum pinnatum (Lam.).

Palabras clave: Medicamentos a base de hierbas. Salud urbana. Etnobotánica.

\footnotetext{
${ }^{1}$ Graduando em Agronomia, com ênfase em agroecologia e agricultura familiar. Universidade da Integração Internacional da Lusofonia Afro-Brasileira (Unilab). Email: henriquepinheiro@aluno.unilab.edu.br Orcid: https://orcid.org/0000-0003-3967-7361

${ }^{2}$ Graduanda em Agronomia, com ênfase em agroecologia e agricultura familiar. Universidade da Integração Internacional da Lusofonia Afro-Brasileira (Unilab). Email: anakarolyneancelmofreire@gmail.com
} 


\section{INTRODUÇÃO}

Até o advento da indústria farmacêutica nos séculos XIX e XX, as plantas constituíam a base da grande maioria dos remédios usados na medicina tradicional dos povos e a sua utilização no alívio e cura das enfermidades é anterior à própria agricultura, sendo chamada de fitoterapia. Seu registro mais antigo foi encontrado no Irã e, segundo os arqueólogos, datam de mais de sessenta mil anos atrás, quando o ser humano nem tinha adotado a agricultura (REZENDE \& COCCO, 2002).

Já os indígenas conheciam metodicamente as utilidades medicinais de várias plantas e as ensinaram aos portugueses na medida em que os auxiliavam por bem ou por mal a conhecer a fauna e a flora sul-americana, bem como a fazerem o uso das suas potenciais utilidades alimentares e medicinais. Os lusitanos, por sua vez, deram sua contribuição na construção da fitoterapia brasileira ao trazerem outras espécies para a América; essas “novas" plantas vieram de regiões da Europa e da Ásia (MIRANDA, 2017).

A flora e fauna nordestina se diferenciam do restante do país por abrigarem o bioma caatinga, único ecossistema exclusivamente brasileiro. Muitas das poucas espécies de árvores a permanecerem verdes nesse bioma durante a estiagem, como a carnaúba e o babaçu, têm inúmeras utilidades para as populações rurais, sendo o preparo de remédios apenas uma delas. Outras espécies vegetais de menor porte podem parecer apenas uma planta espontânea durante o período chuvoso na região, mas, de acordo com a sapiência dos povos, possuem propriedades fitoterápicas de muita valia para as populações rurais que, muitas vezes, recorrem a elas por não terem um acesso a atendimento médico qualificado.

No interior do Estado do Ceará, a região do Maciço de Baturité conta com uma flora mais diversificada do que a maior parte do estado devido à altitude elevada da área, e à proximidade do litoral, onde ocorre maior regularidade da quadra chuvosa. Esses fatores favorecem o crescimento da vegetação típica da mata atlântica somada a zonas de transição de caatinga. A maior biodiversidade dessa região implica na existência de uma fitoterapia mais complexa e que é válida ser melhor estudada em meios acadêmicos para possíveis correções e aperfeiçoamentos.

Vale lembrar que recentemente o Sistema Único de Saúde (SUS) incluiu a fitoterapia dentro da categoria de terapias alternativas. A indicação de remédios fitoterápicos dentro do sistema hospitalar pode diminuir o apelo aos remédios sintéticos, bem como a compra e venda ilegal dos mesmos. Para que esse processo transcorra dentro da devida legalidade faz-se 
necessário a identificação correta das espécies bem como uma revisão detalhada do quanto já se pesquisou e identificou sobre cada uma delas.

Ressalta-se que, apesar de ser tão antiga, a identificação de plantas medicinais não tem muito respaldo dentro da área da agronomia convencional devido a estar mais relacionada ao extrativismo eventual dessas ervas quando elas germinam espontaneamente do que ao cultivo das mesmas. Esse cultivo, quando ocorre, é geralmente em pequena escala e para consumo próprio. No entanto, hoje, em grandes cidades, já se começa a existir um mercado consumidor constituído majoritariamente por pessoas sem espaço para cultivar suas plantas e que acabam por virarem a clientela de feirantes e da tradicional indústria do chá. Essa indústria emergente tem experimentado aumentar os seus prestígios, oferecendo uma diversidade cada vez maior de espécies nacionais e estrangeiras e já depende de áreas de cultivo suficientemente relevantes para a atuação de agrônomos especializados.

O presente trabalho se presta a contribuir com a difusão da fitoterapia ao identificar três amostras de plantas medicinais recolhidas em três diferentes pontos do Maciço de Baturité. Essas amostras foram depositadas no Herbário da Universidade Internacional da Lusofonia AfroBrasileira, localizada no município de Redenção, no Estado do Ceará, e poderão futuramente contribuir para a pesquisa não só botânica como a medicinal.

\section{METODOLOGIA}

Para a realização deste trabalho houve uma etapa de pesquisa de campo, utilizando-se de metodologias exploratórias. As amostras de Alfavaca (Ocimum basilicum L.) - FIGURA 1, e de Boldo-da-terra (Plectranthus barbatus A.) - FIGURA 2, foram coletadas em um quintal residencial na zona urbana do município de Barreira, no Ceará. O local não é manejado e, assim, a matriz não tem nenhuma interferência antrópica direta no seu desenvolvimento. O solo parece ideal uma vez que diversas outras plantas medicinais crescem no ambiente em questão. A amostra de CoiramaBranco (Bryophyllum pinnatum (Lam.), FIGURA 3, foi coletada no Sítio Vitória, zona rural do município de Redenção-Ceará. A matriz é plantada em vaso e recebe cuidados periódicos da proprietária do local - como rega, adubação e tratos culturais (poda, remoção de plantas espontâneas etc.).

Para a coleta, utilizou-se uma tesoura de poda para cortar as hastes, jornais para proteção das mesmas (uma folha para cada uma das amostras) e sacos plásticos para transporte. Além desses materiais, utilizou-se também uma câmera fotográfica para fazer os registros das coletas, uma trena 
para fazer a medição da planta matriz e um aplicativo de geolocalização para a coleta dos dados geográficos de latitude, longitude e altitude.

FIGURA 1 - Coleta de Alfavaca

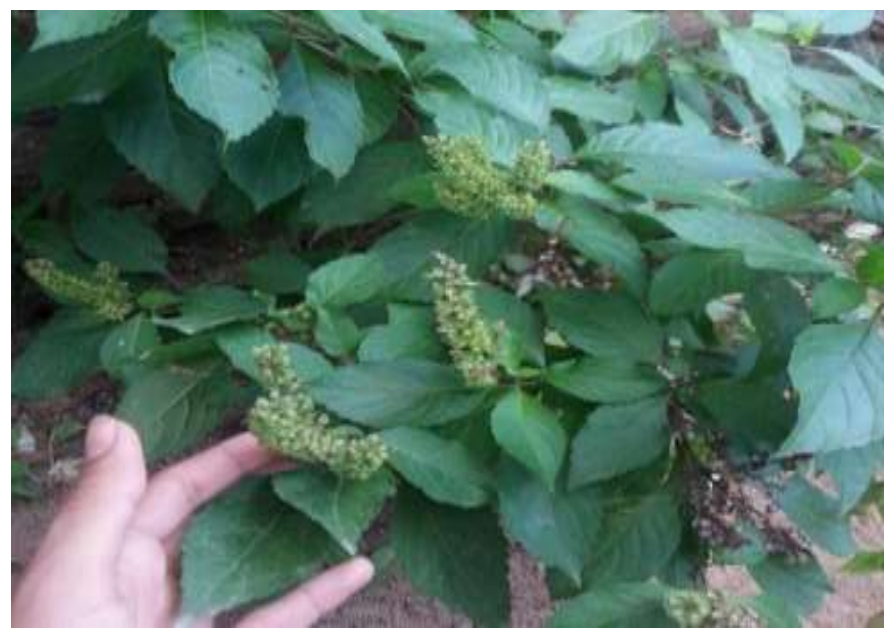

Fonte: Autores

FIGURA 2 - Coleta do boldo-da-terra

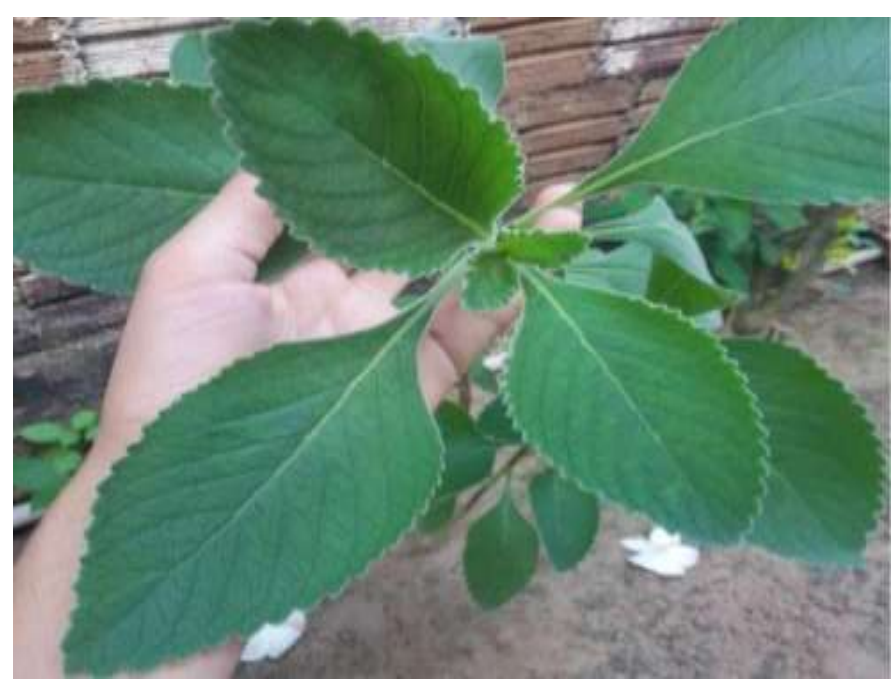

Fonte: Autores. 


\section{FIGURA 3 - Coleta do coraima-branco}

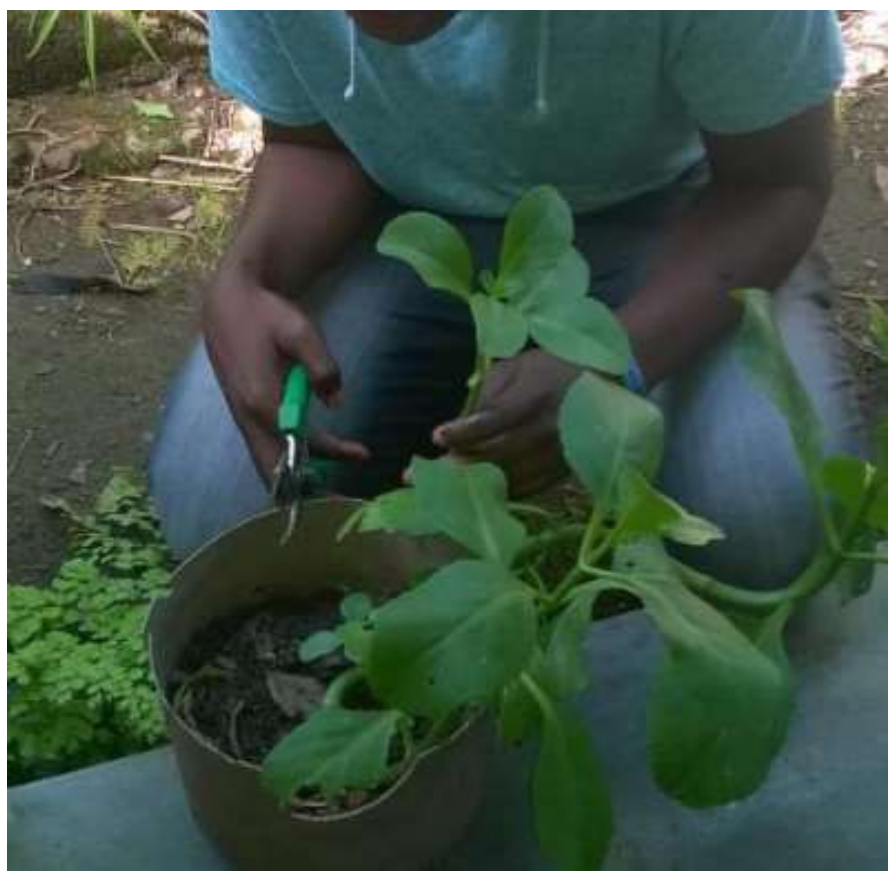

Fonte: Autores

Após a coleta das amostras, iniciou-se, no dia 22 de março de 2018, a etapa de laboratório, que foi dividida em três etapas: prensagem e secagem do material; verificação de material e choque térmico e confecção das exsicatas. No dia 22 de março do mesmo ano, a equipe se reuniu no laboratório para a montagem das prensas (duas grades de madeira utilizadas para prensar o material coletado). As amostras foram devidamente higienizadas e medidas para logo após serem organizadas entre folhas de jornal e papelão para reter a umidade das amostras (FIGURA 4).

Posteriormente, foram colocadas entre duas pranchas de madeira com dimensões de $40 \mathrm{~cm} \times 30 \mathrm{~cm}$, e atadas com corda para exercer uma determinada pressão sobre o material. Logo após a montagem da prensa, ela foi colocada em uma estufa (FIGURA 5) controlada com temperatura entre $60^{\circ} \mathrm{C}$ e $70^{\circ} \mathrm{C}$. O material ficou submetido a esse processo de secagem por 72 horas. 
FIGURA 4 - Organização da pré-secagem

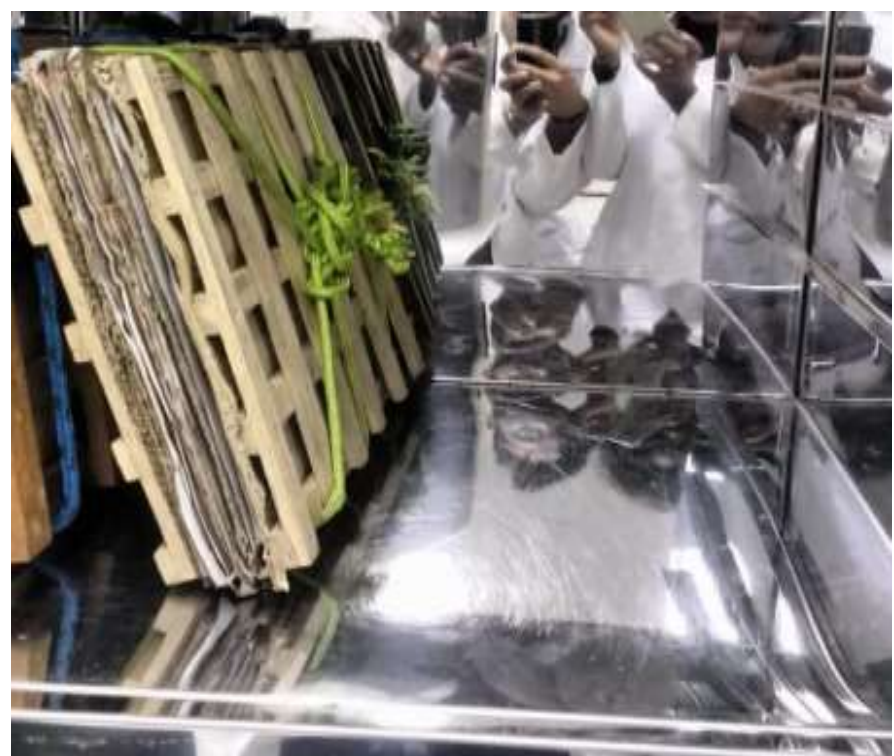

Fonte: Autores

\section{FIGURA 5 - Secagem em estufa}

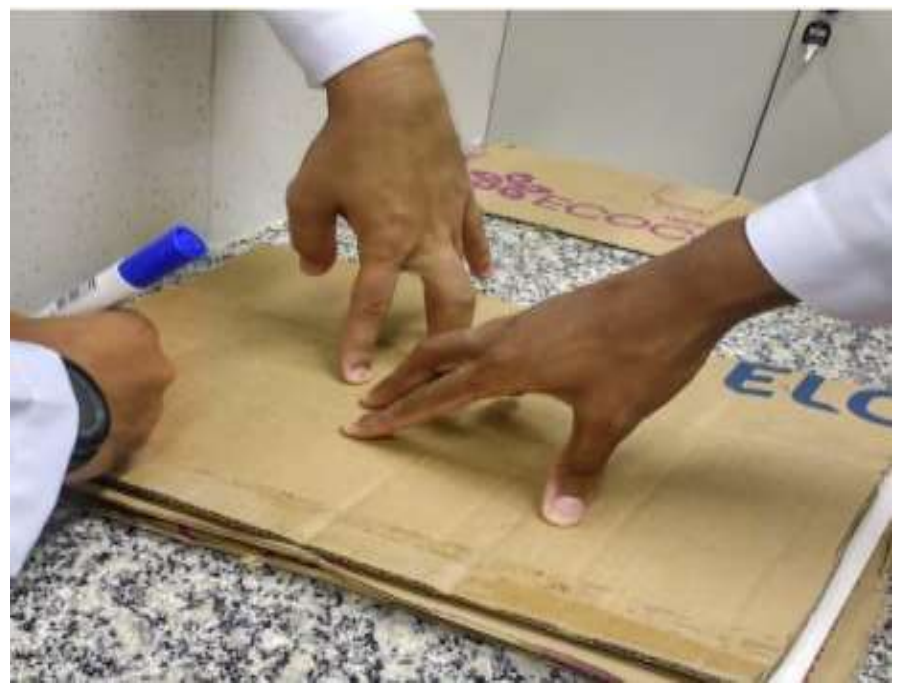

Fonte: Autores

A segunda parte da etapa de laboratório procedeu na semana seguinte, no dia 29 de março. Nessa etapa, a equipe verificou o estado de secagem do material e detectou que as amostras estavam prontas para serem retiradas da estufa e submetidas ao choque térmico, processo que visa a eliminação de possíveis patógenos que possam contaminar as amostras. As amostras foram colocadas em um saco plástico e dentro de uma geladeira (FIGURA 6). 
O material ficou submetido a esse processo por mais 72 horas. A terceira parte foi realizada no dia 10 de maio de 2018 e consistiu no recorte do papel de madeira e da cartolina e confecção (costura) das exsicatas (FIGURA 7).

O papel foi cortado em conformidade com as medidas fornecidas no início da atividade, com o intuito de criar pastas com padrão para proteger as exsicatas. As amostras foram costuradas em cartolina e armazenadas dentro das pastas.

\section{FIGURA 6 - Choque térmico}

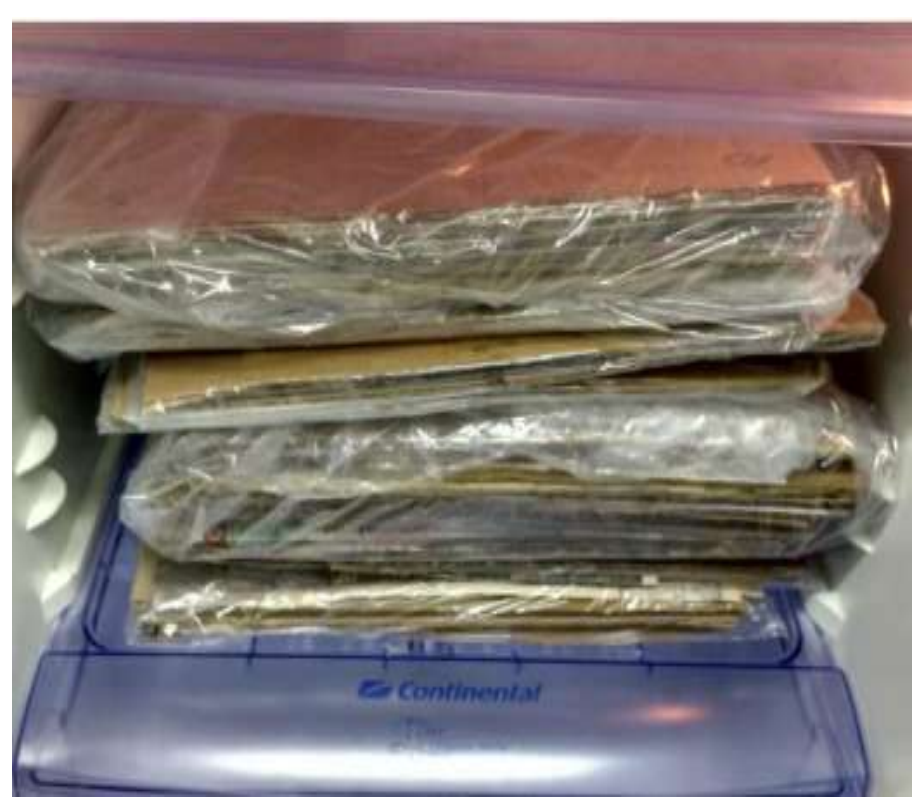

Fonte: Autores 


\section{FIGURA 7 - Montagem das exsicatas}

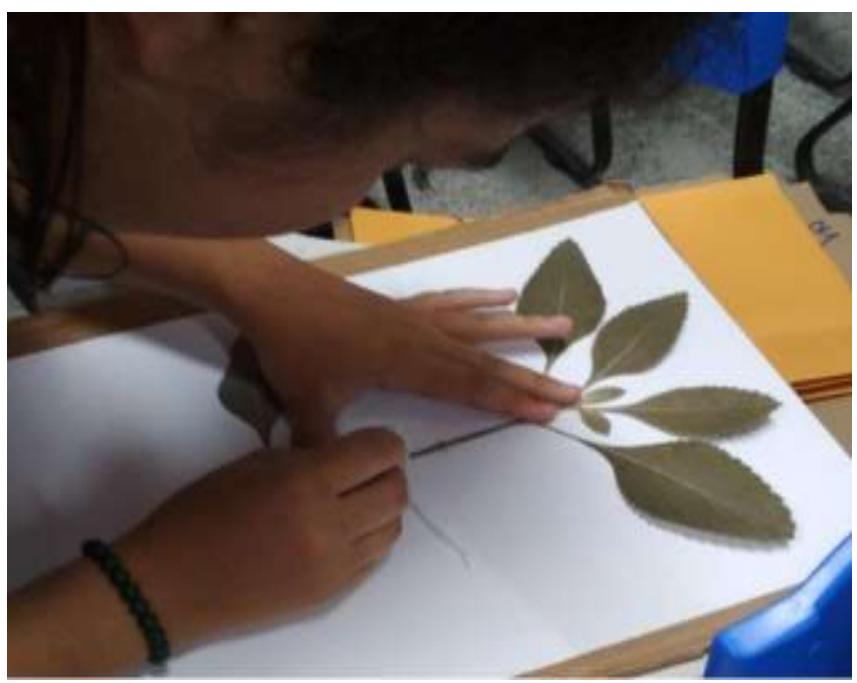

Fonte: Autores

\section{RESULTADOS E DISCUSSÕES}

A Alfavaca (Ocimum basilicum L.), uma planta bastante aromática muito frequente nos jardins das residências do Maciço de Baturité, caracteriza-se por apresentar flores e folhas com perfume agradável e por ter um porte pequeno e organizado para jardins; é utilizada tanto medicinalmente como também como condimento em alimentos, sendo indicada para fitoterapia popular para alívio de tosse e outras complicações no trato respiratório. De acordo com De Sá Sobrinho e Garcia (1997), essa planta pode ter ação anti-inflamatória, estimulante, antiasmático e antiespasmódicos.

A espécie se mostra como uma ótima alternativa a se agregar valor econômico, pois o mercado está cada vez mais se interessando por produtos naturais, tornando a procura frequente e a baixa disponibilidade atraente para novos investimentos. Pereira e Moreira (201, p 8) afirmam que:

Estudos têm demonstrado a possibilidade da produção de óleo essencial rico em linalol, substância utilizada na fabricação de cosméticos a partir de espécies de manjericão. Por se tratar de plantas que se desenvolvem melhor em regiões de climas quentes e amenos, características próprias da região Nordeste do Brasil, o cultivo de manjericão constitui uma alternativa geradora de emprego e renda para pequenos agricultores. 
Quadro 1 - Sinopse de Classificação taxonômica da espécie

\begin{tabular}{|l|l|}
\hline Classificação & \\
\hline Nome científico & Ocimum basilicum Linnaeus \\
\hline Nome Popular & Alfavaca \\
\hline Família botânica & Lamiaceae \\
\hline Clima & Subtropical e temperado quente e úmido \\
\hline Origem & Índia \\
\hline Autor & Carl Nilsson Linnaeus \\
\hline
\end{tabular}

Fonte: Linnaeus (1753)

A partir da descrição feita por Carl Nilsson Linnaeus (1735), Quadro 1, pode-se estabelecer os padrões para a identificação e categorização a nível de morfologia, Quadro 2.

\section{Quadro 2 - Caracteres Morfológicos}

\begin{tabular}{|l|l|}
\hline Parte vegetal & Morfologia \\
\hline Hábito & Subarbusto, planta anual \\
\hline Folha & Alternas, ovalado-lanceoladas e com margens duplamente dentadas \\
\hline Flores & $\begin{array}{l}\text { Roxo Pálidas, pequenas, bissexuais, tubulares, zigomorfas, } \\
\text { oligostêmones e diclamídeas; Ovário bicarpelar e bilocular; Gineceu } \\
\text { com estilete ginobásico e estigma bífido; Androceu longitudinal cálice } \\
\text { simsépalo; corola simpétala. }\end{array}$ \\
\hline Inflorescência & Racemosa \\
\hline Semente & Esféricas \\
\hline Fruto & Cápsula \\
\hline
\end{tabular}

Fonte: Linnaeus (1753)

A partir da observação da morfologia da cultura, com a revisão das características morfológicas já descritas na botânica, foi feita a elaboração com os termos técnicos-científicos do Quadro 3, com a descrição da taxonomia vegetal correta e a criação das chaves dicotômicas. 
Quadro 3 - Taxonomia Vegetal

\begin{tabular}{|c|c|}
\hline Reino & Plantae \\
\hline Divisão & Magnoliophyta \\
\hline Classe & Magnolopsida \\
\hline Ordem & Lamiales \\
\hline Família & Lamiaceae \\
\hline Gênero & Ocimum \\
\hline Espécie & gratissimum \\
\hline
\end{tabular}

Fonte: Autores

\section{Chave para Identificação a nível de família}

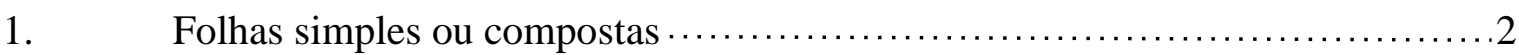

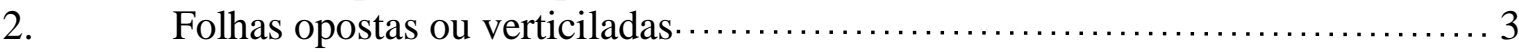

3. Folhas sem estípula e geralmente serrilhadas ou denteadas $\ldots \ldots \ldots \ldots \ldots \ldots \ldots \ldots$

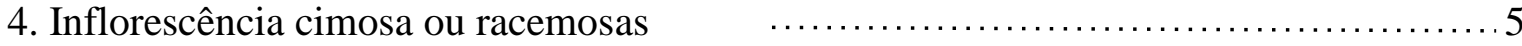

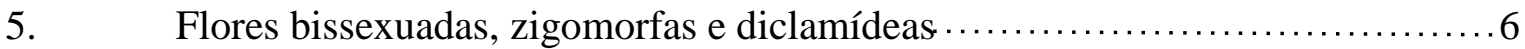

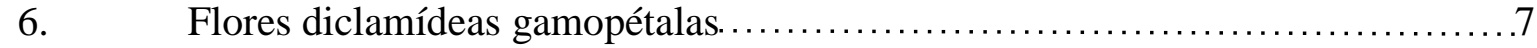

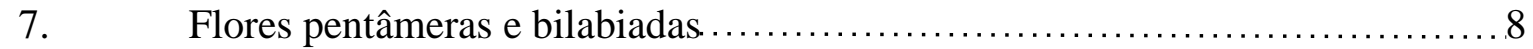

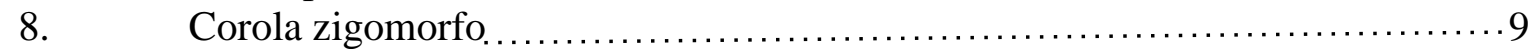

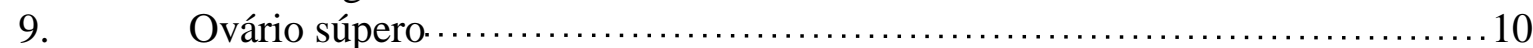

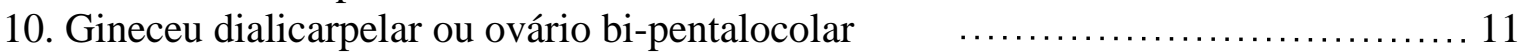

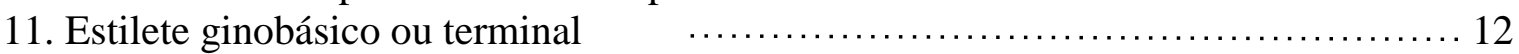

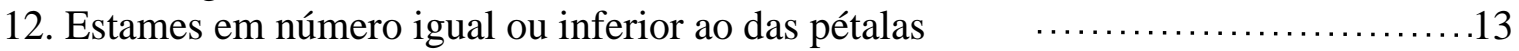

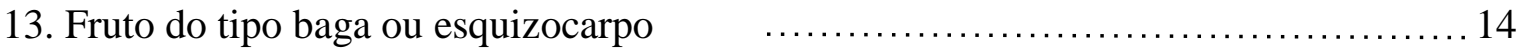

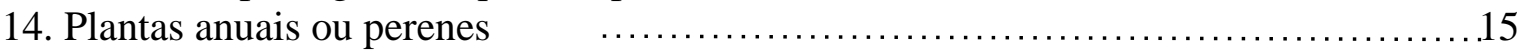

15. Ervas, arbustos, subarbustos e raramente árvores $\quad$......................miaceae

\section{Chave para Identificação a nível de gênero}

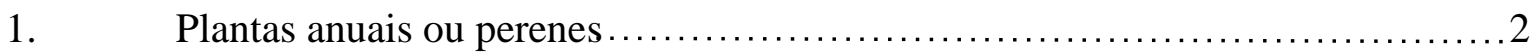

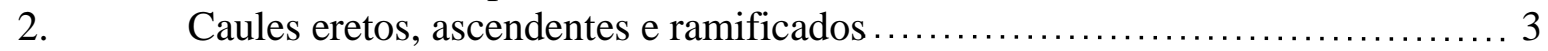

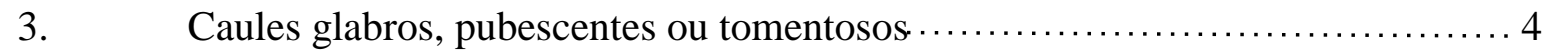

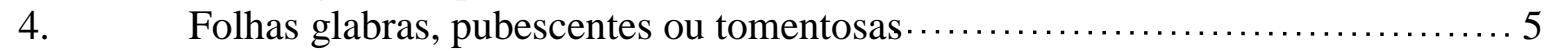

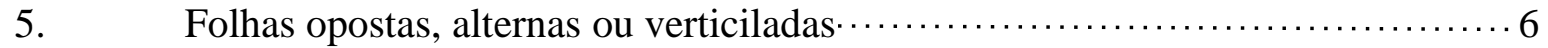

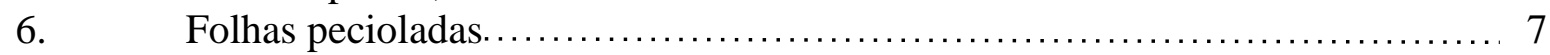

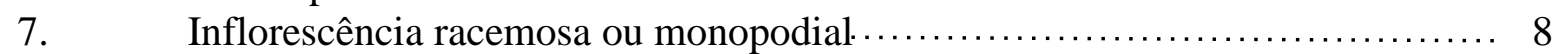

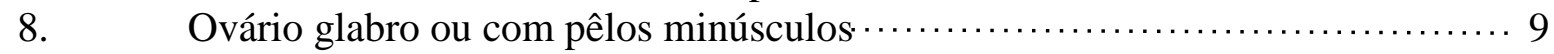

9. Cálice bilabiado, com lábio superior grande e redondo, lábio inferior com 4

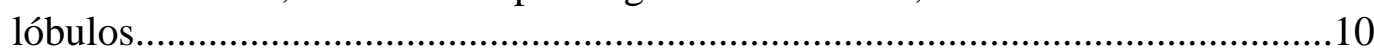

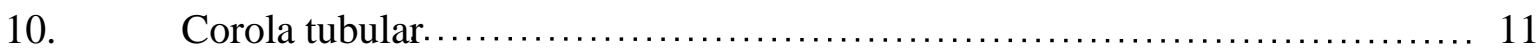


11. Corola bilabiada, com lábio superior com 4 lóbulos, lábio inferior achatado e côncavo 12

12. 4 estames heterodínamos 13

13. Anteras dorsifixas 14

14. Frutos ovóides, obovados ou semiesféricos

15. Ervas, arbustos ou subarbustos

Ocimum L.

\section{Chave para Identificação a nível de espécie}

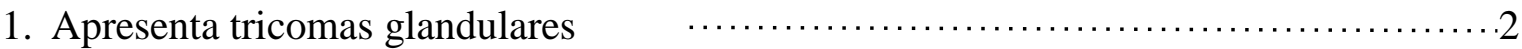

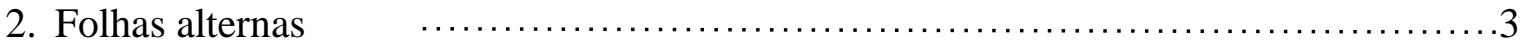

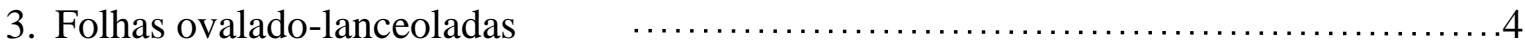

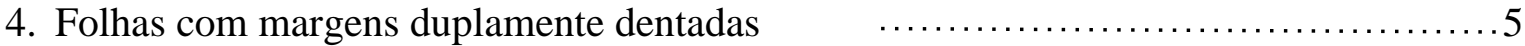

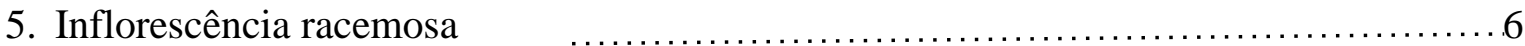

6. Flores roxas pálidas, pequenas, bissexuadas, tubulares e zigomorfas $\quad \ldots \ldots \ldots \ldots . \ldots 7$

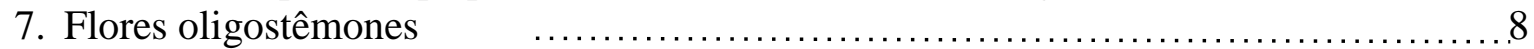

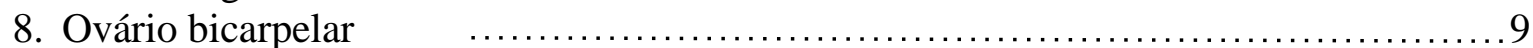

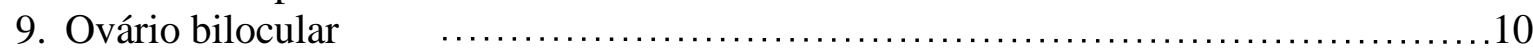

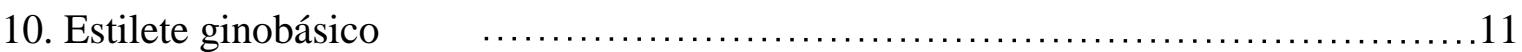

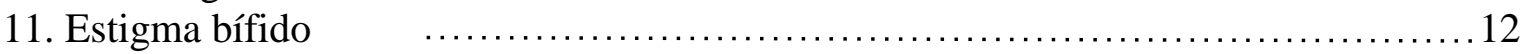

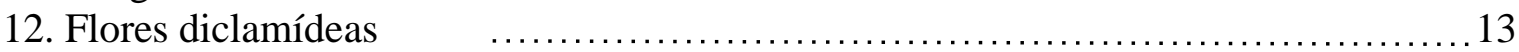

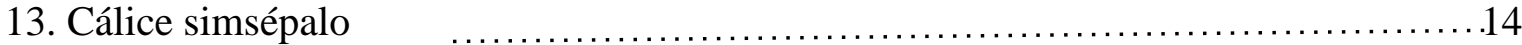

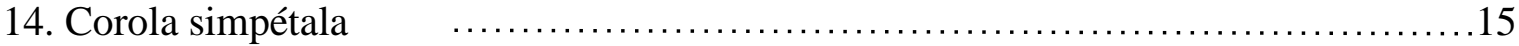

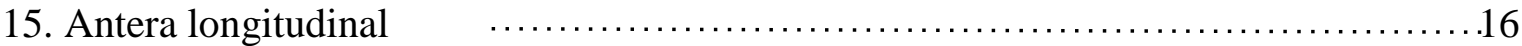

16. Frutos do tipo cápsula e possuem quatro sementes esféricas $\quad \ldots \ldots \ldots \ldots \ldots \ldots \ldots \ldots \ldots \ldots \ldots \ldots \ldots 17$

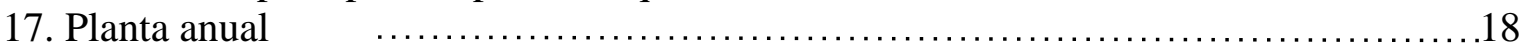

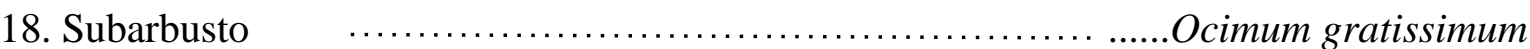

Linnaeus.

A segunda amostra coletada e classificada seguiu as constatações demonstradas pelos estudos do botânico Henry Charles Andrews (Quadro 4) primeiro a classificá-la em 1810, e, a partir destes padrões, foi possível fazer sinopse de classificação taxonômica e, assim, a identificação e classificação a nível de morfologia (Quadro 5), o que possibilitou a elaboração do Quadro 6 com a taxonomia vegetal da espécie e a confecção das chaves dicotômicas a nível de gênero, família e espécie da cultura.

O Boldo-da-Terra (Plectranthus barbatus Andrews) é uma das plantas mais citadas na literatura de plantas medicinais por ser amplamente usada pela medicina tradicional. Como a maioria das plantas medicinais, ela é utilizada fresca, como uma forma de garantir que todos os compostos responsáveis pelo efeito medicinal estejam mais concentrados e, assim, é inviável a estocagem e a comercialização da planta fresca, pois a mesma possui um elevado teor de água na sua composição, o que facilitaria a sua deterioração (RODRIGUES et al., 2011). 
São muitas as descrições que citam as propriedades medicinais do Boldo-da-Terra, muitas destas repassadas há gerações e que agregaram valores cada vez mais qualificados ao longo do tempo e com o surgimento de cada vez mais novos estudos sobre. No Brasil, de acordo com a bióloga Sandra Zorat Cordeiro, do Instituto de Biociências da Universidade Federal do Estado do Rio de Janeiro (UNIRIO):

As propriedades terapêuticas do Plectranthus barbatus são muito conhecidas no tratamento de problemas digestivos e dor de estômago, sendo consumido preferencialmente como chá, cuja recomendação é disseminada entre toda a população brasileira. Mas o boldo-africano tem ainda muitas outras aplicações: no tratamento de dor de dente, distúrbios gengivais, problemas de pele (como queimaduras, alergias, micoses, eczemas e feridas), queda de cabelo, infecções de garganta, ouvido e olhos, reumatismo, dores musculares, problemas cardíacos, circulatórios e sanguíneos. No Brasil, ainda há relatos de seu uso no tratamento de malária. Grande parte destas aplicações decorrem das cientificamente comprovadas atividades antibacterianas, antivirales, antifúngicas e contra protozoários, citotóxicas e antitumorais, e ainda estimuladoras do sistema imunológico (CORDEIRO, 2020, s/n).

Quadro 4 - Sinopse de Classificação taxonômica da espécie

\begin{tabular}{|l|l|}
\hline Nome científico & Plectranthus barbatus Andrews \\
\hline Nome Popular & Boldo-da-Terra \\
\hline Família botânica & Lamiaceae \\
\hline Clima & Tropical e subtropical \\
\hline Origem & Índia \\
\hline Autor & Henry Charles Andrews \\
\hline
\end{tabular}

Fonte: Andrews (1810)

\section{Quadro 5 - Caracteres Morfológicos}

\begin{tabular}{|l|l|}
\hline Parte vegetal & Morfologia \\
\hline Hábito & Arbustiva, perene \\
\hline Folha & $\begin{array}{l}\text { Simples, flexível (mesmo quando seca), ovaladas, opostas, margens } \\
\text { dentadas e pilosas e nervuras basais direcionadas para o ápice. }\end{array}$ \\
\hline Flores & Azuis localizadas em racemos terminais \\
\hline Inflorescência & Racemosa apical \\
\hline Semente & - \\
\hline Fruto & - \\
\hline
\end{tabular}


Quadro 6 - Taxonomia Vegetal

\begin{tabular}{|l|c|}
\hline Reino & Plantae \\
\hline Divisão & Magnoliophyta \\
\hline Classe & Magnolopsida \\
\hline Ordem & Saxifragales \\
\hline Família & Crassulaceae \\
\hline Gênero & Bryophyllum \\
\hline Espécie & pinnatum \\
\hline
\end{tabular}

Chave para Identificação a nível de família da Plectranthus barbatus Andrews

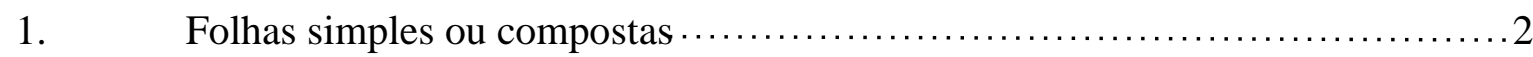

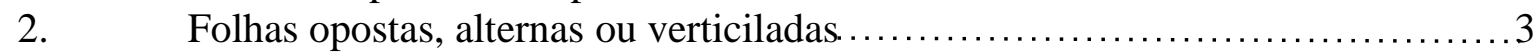

3. Folhas sem estípulas e geralmente serrilhadas ou denteadas...................

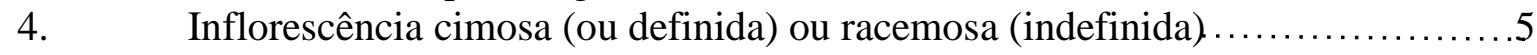

5. Flores bissexuadas, zigomorfas e diclamídeas ................................6 6

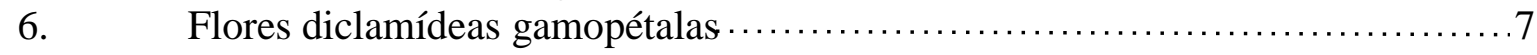

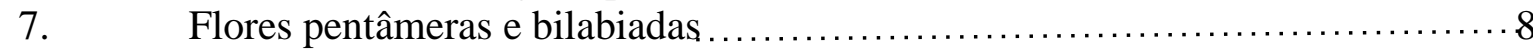

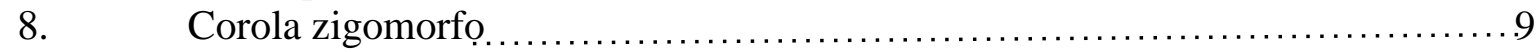

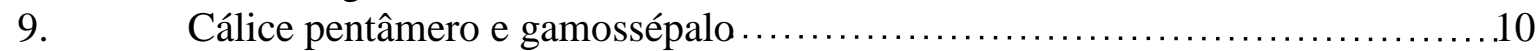

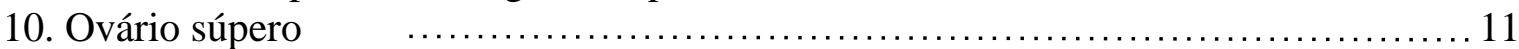

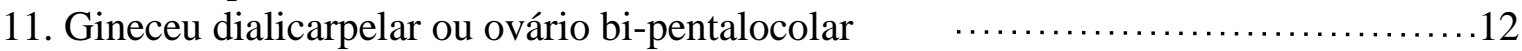

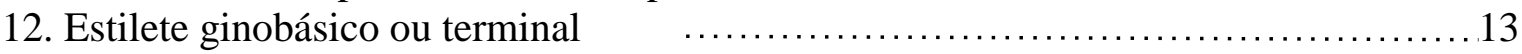

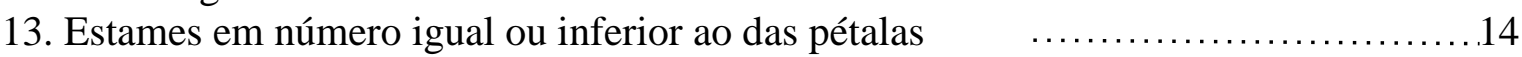

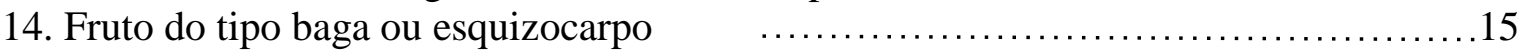

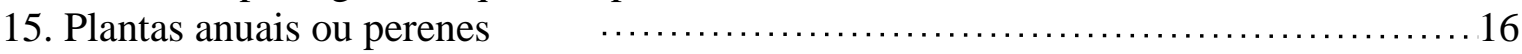

16. Ervas, arbustos, subarbustos e raramente árvores $\quad \ldots \ldots \ldots \ldots \ldots \ldots \ldots$...................eae

\section{Chave de identificação a nível de gênero da Plectranthus barbatus Andrews}

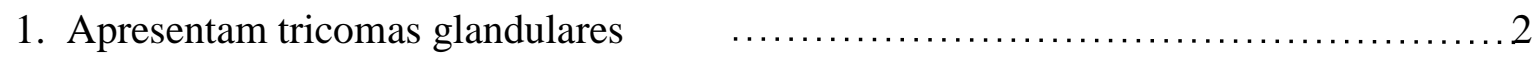

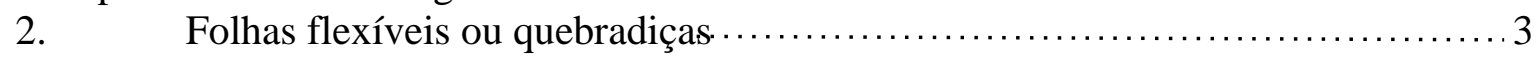

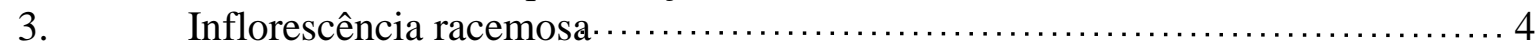

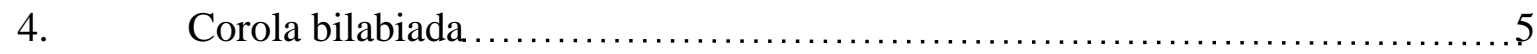

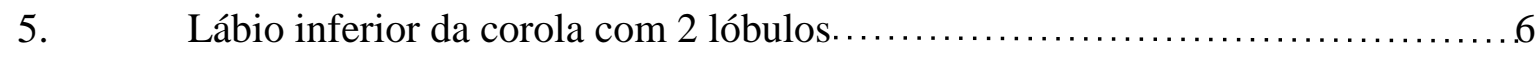

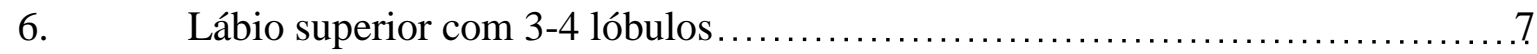

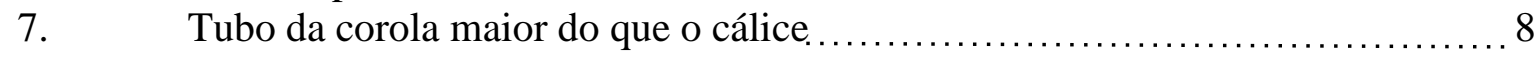

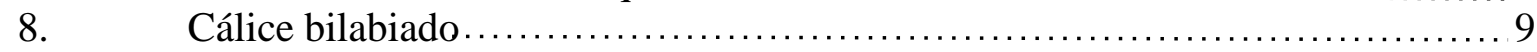

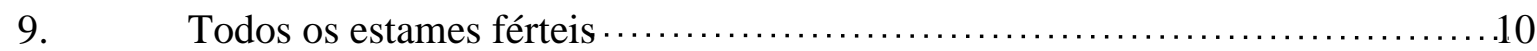

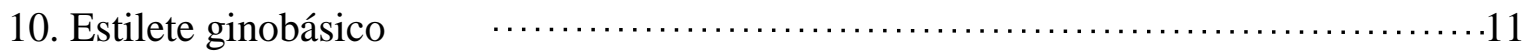

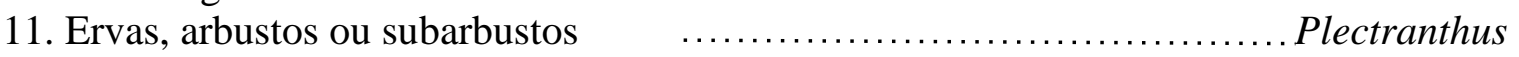




\section{Chave para Identificação a nível de espécie da Plectranthus barbatus Andrews}

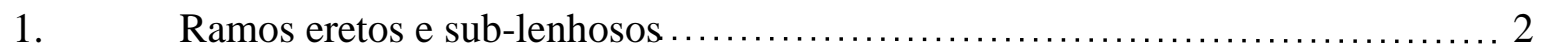

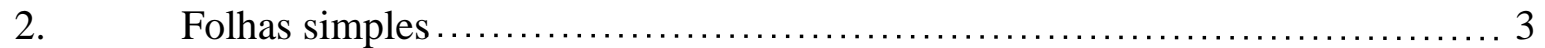

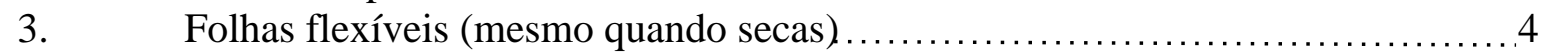

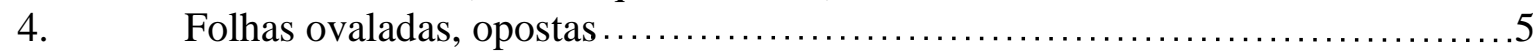

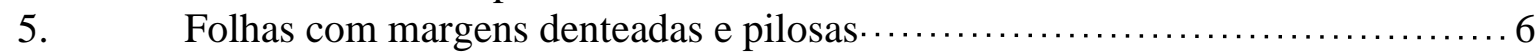

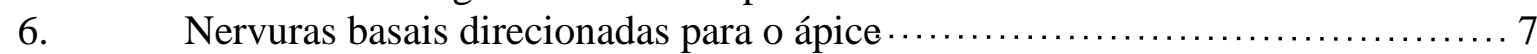

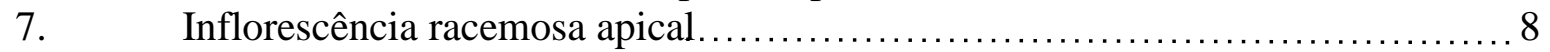

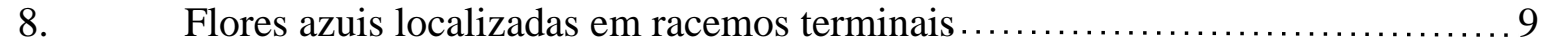

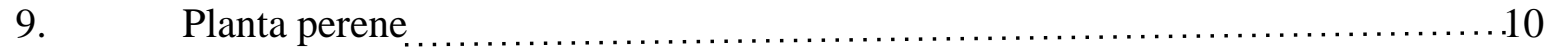

10. Planta arbustiva $\quad \ldots \ldots \ldots \ldots \ldots \ldots \ldots \ldots \ldots \ldots \ldots \ldots \ldots \ldots \ldots$ Plectranthus barbatus Andrews

A terceira amostra coletada foi o Coirama-Branco (Bryophyllum pinnatum (Lam.)). Utilizada, geralmente, por meio de cataplasma da folha e como suco para ser ingerido, essa espécie tem diversas utilidades medicinais já descritas e é amplamente utilizada para alívio de inflamações. Alguns outros benefícios descritos são: analgésico, antibacteriana, antifúngica, antigástrico, antipirético, cicatrizante, imunoestimulante, tônica pulmonar, calmante, utilizada para controlar a atividade antimicrobiana de gânglios e infecções de vias urinárias e genitais. Além disso, é usada também como contra a tosse (FORTE et al., 2007). Nassis et al. (1991) afirmam que essa espécie pode ser utilizada através da ingestão do suco para o tratamento da tosse, dor de garganta, inflamações, hematomas, glaucoma e medicação tópica em afecções cutâneas de natureza alérgica.

Essa espécie foi descrita primeiramente pelo naturalista francês Jean-Baptiste Lamarck no ano de 1786. A partir dessa descrição, foi feita a sinopse de classificação taxonômica (Quadro 7) da mesma, pontapé fundamental para a categorização da sua classificação dos seus caracteres morfológicos (Quadro 8) e, também, para o estudo e pesquisa dos termos correspondentes para a elaboração do quadro de taxonomia vegetal (Quadro 9) e das suas chaves dicotômicas a nível de família e espécie.

Quadro 7 - Sinopse de Classificação taxonômica da espécie

\begin{tabular}{|l|l|}
\hline Nome científico & Bryophyllum pinnatum (Lam.) \\
\hline Nome Popular & Coirama-Branco \\
\hline Família botânica & Crassulaceae \\
\hline Clima & Tropical e subtropical \\
\hline Origem & África e Índia \\
\hline Autor & Jean-Baptiste Lamarck \\
\hline
\end{tabular}

Fonte: Lamarck (1786) 


\section{Quadro 8 - Caracteres Morfológicos}

\begin{tabular}{|l|l|}
\hline Parte vegetal & Morfologia \\
\hline Hábito & Herbácea-subarbustiva. \\
\hline Folha & $\begin{array}{l}\text { Opostas, agrupadas ao longo do caule e geralmente de coloração } \\
\text { vermelha nas extremidades. }\end{array}$ \\
\hline Flores & $\begin{array}{l}\text { Hermafroditas. Sépalas unidas por mais de 3/4 do seu comprimento; } \\
\text { Pétalas tetrâmeras Corola petaloide; Androceu hemodinâmico, estames } \\
\text { dialistêmones longitudinal ou rimosa; Gineceu dicarpelar ou } \\
\text { pluricelular, estilete caracteriza-se como variável e ramificado e estigma } \\
\text { terminal e variável. }\end{array}$ \\
\hline Inflorescência & Cimosa \\
\hline Semente & \\
\hline Fruto & \\
\hline
\end{tabular}

Quadro 9- Taxonomia Vegetal

\begin{tabular}{|l|c|}
\hline Reino & Plantae \\
\hline Divisão & Magnoliophyta \\
\hline Classe & Magnolopsida \\
\hline Ordem & Lamiales \\
\hline Família & Lamiaceae \\
\hline Gênero & Plectranthus \\
\hline Espécie & barbatus \\
\hline
\end{tabular}




\section{Chave para Identificação a nível de família da Bryophyllum pinnatum (Lam.)}

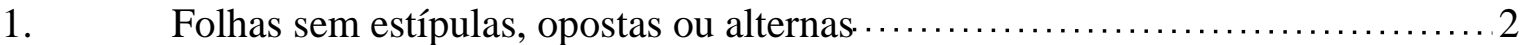

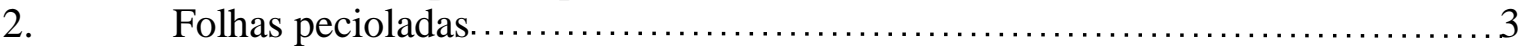

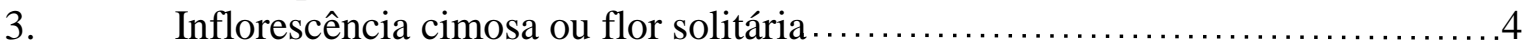

4. Flores geralmente bissexuadas, raramente unissexuadas...................... 5

5. Flores actinomorfas, hipóginas ou levemente períginas ...................... 6

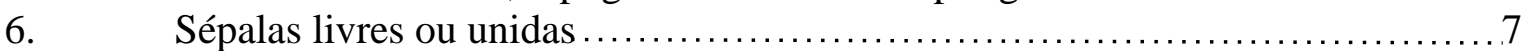

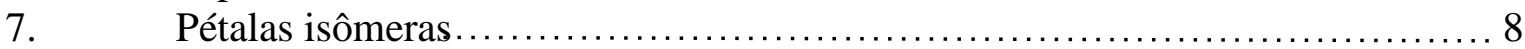

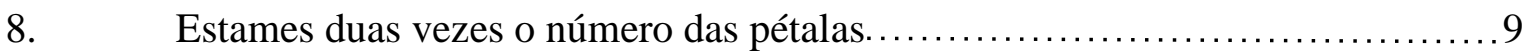

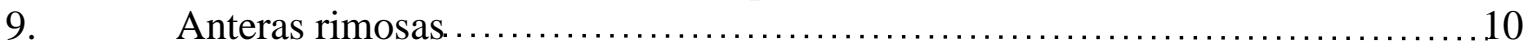

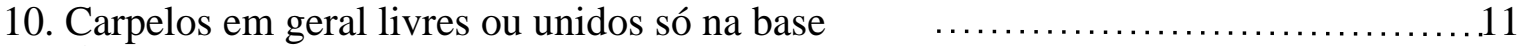

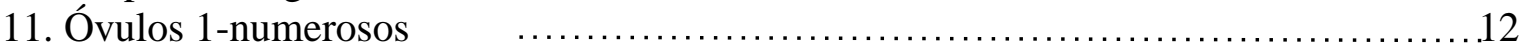

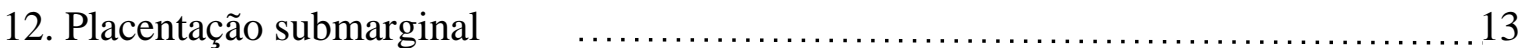

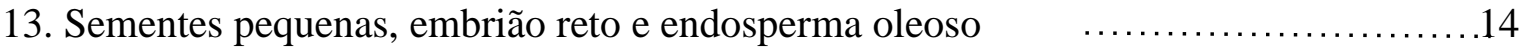

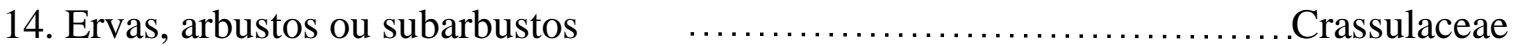

\section{Chave para Identificação a nível de espécie da Bryophyllum pinnatum (Lam.)}

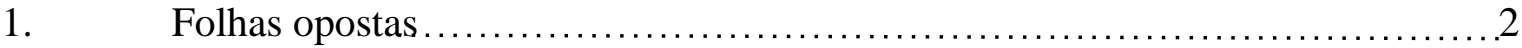

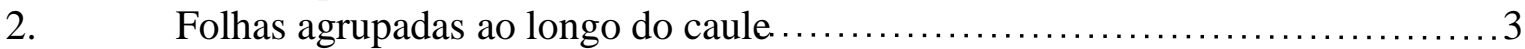

3. Folhas geralmente de coloração vermelha nas extremidades $\ldots \ldots \ldots \ldots \ldots \ldots \ldots \ldots$

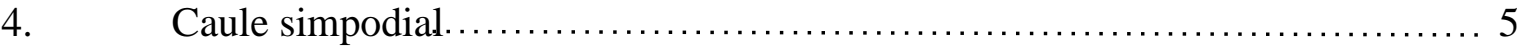

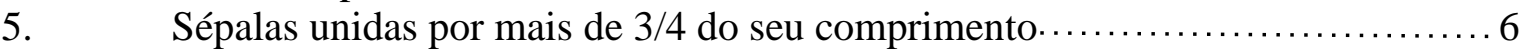

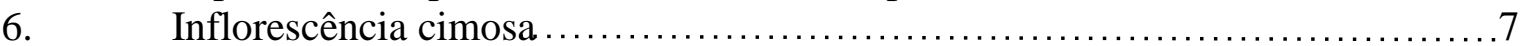

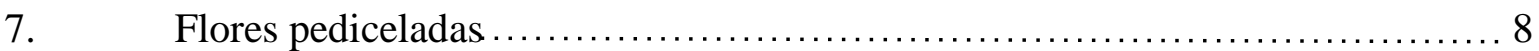

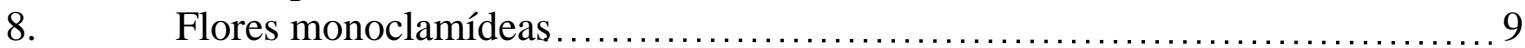

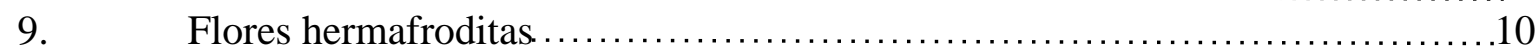

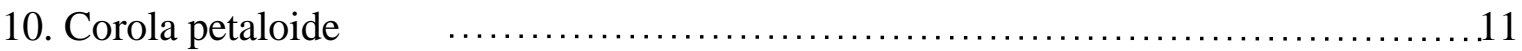

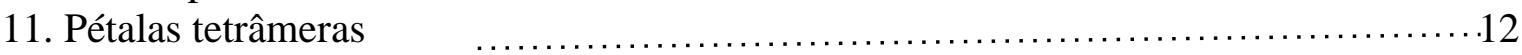

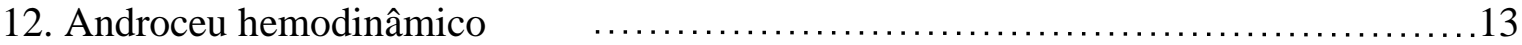

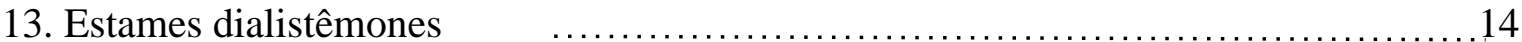

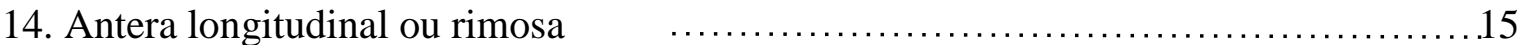

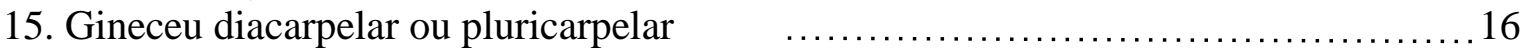

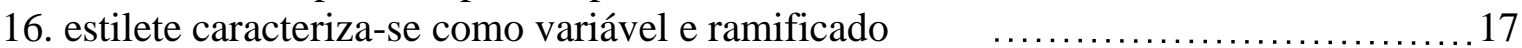

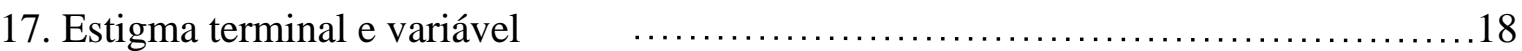

18. Planta herbácea-subarbustiva $\quad$................... Bryophyllum pinnatum (Lam.) 


\section{CONSIDERAÇÕES FINAIS}

O presente trabalho permitiu desenvolver - a partir dos direcionamentos e pesquisas levantadas relacionadas à identificação taxonômica botânica - a categorização científica das espécies de cunho etnobotânicas coletadas. Existe uma rica fonte bibliográfica disponível para consultas, de forma que é possível assegurar o desenvolvimento de novas pesquisas e colaborações para a identificação taxonômica de espécies ainda não catalogadas e que são usadas pela população, assim como a elaboração de novas chaves dicotômicas que podem ser utilizadas para uma identificação direcionada e precisa de algumas espécimes para aprofundamentos científicos.

É de suma importância que mais estudos relacionados a identificação científica de propriedades medicinais em espécies etnobotânicas sejam publicados e divulgados para que possam surgir novos medicamentos fitoterápicos que tenham um grau de confiabilidade para uso da população. Além disso, essas culturas que são usadas popularmente mostram-se como uma alternativa atraente para a geração de emprego e de agregação de valores comerciais para produção destas, além de possibilitar uma renda extra para famílias em vulnerabilidade social que trabalham com agricultura familiar, já que a busca por ervas medicinais frescas (in natura) em mercados é bastante frequente e a disponibilidade e diversidade ainda é limitada na maior parte do país.

\section{REFERÊNCIAS}

ALESSANDRA, S. S. de O. et al. ASPECTOS DA ORGANOGRAFIA DA ESPÉCIE

FOLHA-DA-FORTUNA. Disponível em: $\langle$ http://www.botanica.org.br/trabalhoscientificos/64CNBot/resumo-ins19977-id4428.pdf>. Acesso em: 09 mai. 2018.

ANDREWS, Henry Charles. The botanist's repository: for new, and rare plants. The author, 1797.

BADKE, Marcio Rossato et al. Plantas medicinais: o saber sustentado na prática do cotidiano popular. Escola Anna Nery Revista de Enfermagem, v. 15, n. 1, p. 132-139, 2011.

BLANK, Arie Fitzgerald et al. Caracterização morfológica e agronômica de acessos de manjericão e alfavaca. 2004. 
BORGES, A. M. et al. Determinação de óleos essenciais de alfavaca (Ocimum gratissimum L.), orégano (Origanum vulgare $L_{\text {.) }}$ e tomilho (Thymus vulgaris L.). Rev. bras plantas med, v. 14, n. 4, p. 656-665, 2012.

CHIBLI, Lucas A. et al. Anti-inflammatory effects of Bryophyllum pinnatum (Lam.) Oken ethanol extract in acute and chronic cutaneous inflammation. Journal of ethnopharmacology, v. 154, n. 2, p. 330-338, 2014.

CORDEIRO, Sandra Zorat. Plectranthus barbatus Andrews. Universidade Federal do Rio de Janeiro (online), 2020. Disponível em: http://www.unirio.br/ccbs/ibio/herbariohuni/plectranthusbarbatus-andrews. Acesso em: 23 jan. 2021.

COSTA, M. C. C. D. Uso popular e ações farmacológicas de Plectranthus barbatus Andr. (Lamiaceae): revisão dos trabalhos publicados de 1970 a 2003. Revista Brasileira de plantas medicinais, v. 8, n. 2, p. 81-88, 2006.

DE SÁ SOBRINHO, A. F.; GARCIA, L. C. Alfavaca (Ocimum basilicum L.). Embrapa Amazônia Ocidental-Capítulo em livro científico (ALICE), 1997.

FORTE, T. S.; DIOGO, A. N. M.; MARTINS, R. C. A.; Controle de qualidade: kalanchoe pinnata (lam.) pers.; Anais da 59 $9^{\text {a }}$ Reunião Anual da SBPC, 2007.

HARLEY, R., et al. Lamiaceae in Lista de Espécies da Flora do Brasil. Jardim Botânico do Rio de Janeiro, 2015. Disponível em: <

http://floradobrasil.jbrj.gov.br/jabot/floradobrasil/FB23334>. Acesso em: 12 mai. 2018.

Jardim Botânico da Universidade de Trás-os-Montes e Alto Douro (UTAD).

Disponível em: https://jb.utad.pt/chavedicotomica. Acesso em: 08/05/2018

LAISE DE HOLANDA, C. Andrade; DE ALBUQUERQUE, Ulysses Paulino. El género Ocimum L.(Lamiaceae) en el nordeste del Brasil. In: Anales del Jardín Botánico de Madrid.

Real Jardín Botánico, 1998. p. 43-64.

NASSIS, Cristina De Zotti et al. Estudo da açäo depressora inespecífica do suco extraído das folhas de Bryophyllum calcynum Salisb.(Crassulaceae) sobre o sistema nervoso central: comparaçäo com os efeitos da difenidramina. Arq. méd. ABC, p. 64-8, 1991.

Rede de catálogos polínicos online. Disponível em: < http://chaves.rcpol.org.br/ >. Acesso em: 09 mai. 2018.

RODRIGUES, T. S. et al. Métodos de secagem e rendimento dos extratos de folhas de Plectranthus barbatus (boldo-da-terra) e P. ornatus (boldo-miúdo). Revista Brasileira de Plantas Medicinais, v. 13, n. spe, p. 587-590, 2011. 


\section{FAZ CIÊNCIA, VOL. 23, N. 38, JUL/DEZ DE 2021 - P. 166 - 184}

SILVA, Rosangela Maria da. Jardim dos sentidos e uso múltiplo de plantas no sistema agroflorestal da Universidade de Brasília-Campus Planaltina-DF. 2017.

SOUZA, Vinicius Castro; LORENZI, Harri. Chave de identificação: para as principais famílias de angiospermas nativas e cultivadas do Brasil. 3. ed. São Paulo: Instituto Plantarum de Estudos da Flora, 2014.

VENÂNCIO, Antônio Medeiros et al. Toxicidade aguda e atividade antinociceptiva do óleo essencial do Ocimum basilicum $\mathrm{L}$.

SOUZA, Vinicios Castro. Botânica Sistemática: guia ilustrado para identificação das famílias de fanerógamas nativas e exóticas no Brasil. 2 ed. Nova Odessa, SP: Instituto Plantarum, 2008 